\title{
Twitch Mouth Pressure and Disease Severity in Subjects With COPD
}

\author{
Chunrong Ju PhD MD, Wei Liu MD, and Rong-chang Chen MD
}

\begin{abstract}
INTRODUCTION: Patients with COPD have impaired respiratory muscle strength. Twitch mouth pressure $\left(P_{t w, m}\right)$ in response to magnetic stimulation of the cervical nerve has been suggested to clinically reflect inspiratory muscle strength. However, studies on $\mathbf{P}_{t w, m}$ values and their relationship with disease severity are limited. Thus, we tested the $\mathbf{P}_{t w, m}$ values of subjects with COPD and investigated the relationship of these values with disease severity. METHODS: We recruited 75 COPD patients and 63 age-matched controls. All participants were tested for $P_{t w, m}$, sniff nasal pressure (SNIP), and maximum static inspiratory mouth pressure $\left(\mathbf{P}_{\mathbf{I}_{\max }}\right)$; the BODE (body mass index, air flow obstruction, dyspnea, exercise capacity) index was evaluated for overall severity assessment and the 6-min walk distance (6MWD) was used to determine the exercise capacity of subjects with COPD. RESULTS: Subjects with COPD had markedly lower $\mathbf{P}_{\mathbf{t w}, \mathrm{m}}$ values compared with the controls $\left(10.00 \pm 2.17\right.$ vs $13.66 \pm 2.20 \mathrm{~cm} \mathrm{H}_{2} \mathrm{O}$ for males, $8.83 \pm 0.89$ vs $11.81 \pm 1.98 \mathrm{~cm}$ $\mathrm{H}_{2} \mathrm{O}$ for female; each with $P<.001$ ). The $P_{t w, m}$ values decreased with increasing COPD severity, and similar trends were observed in the SNIP and $\mathbf{P}_{\mathbf{I}_{\max }}$ values. Regression correlation analysis showed that $P_{t w, m}$ values were significantly correlated inversely with the BODE index $(R=0.65$, $P<.001)$ but positively correlated with $6 \mathrm{MWD}(\mathrm{R}=0.59, P<.001)$ in the COPD group; the SNIP values of subjects with COPD were also correlated inversely with their BODE index $(R=0.49$, $P<.001)$ but positively correlated with their $6 \mathrm{MWD}(\mathrm{R}=0.33, P<.005)$. CONCLUSIONS: $P_{\mathrm{tw}, \mathrm{m}}$ values are $26.8 \%$ lower in male subjects with COPD and $25.3 \%$ lower in female subjects with COPD compared with the controls. The $\mathbf{P}_{t w, m}$ values of subjects with COPD decrease with increasing disease severity. $P_{t w, m}$ was better correlated with the BODE index and exercise capacity than SNIP and $\mathbf{P}_{\mathbf{I}_{\max }}$, which suggests that $\mathbf{P}_{t w, m}$ more accurately reflects the overall severity and burden of COPD. Key words: chronic obstructive pulmonary disease; COPD; twitch mouth pressure. [Respir Care 2014;59(7):1062-1070. (C) 2014 Daedalus Enterprises]
\end{abstract}

\section{Introduction}

Patients with COPD have compromised respiratory muscle function, and inspiratory muscle weakness is an inde-

The authors are affiliated with the State Key Laboratory of Respiratory Disease, Guangzhou Institute of Respiratory Disease, First Affiliated Hospital of Guangzhou Medical University, Guangzhou, Guangdong, People's Republic of China.

Dr Ju presented this study in abstract form at the American Thoracic Society International Conference, held May 17-22, 2013, in Philadelphia, Pennsylvania.

This study was supported by Grant 81100034 from the Special Funds of the National Natural Science Foundation of China. The authors have disclosed no conflicts of interest. pendent predictor of all-cause mortality among COPD patients. ${ }^{1}$ Moreover, hypercapnic respiratory failure caused by inspiratory muscle weakness has been recognized as the leading cause of death among COPD patients. ${ }^{2}$ Determining inspiratory muscle strength is therefore useful in evaluating strategies over preventive and therapeutic approaches for improving respiratory muscle strength. Mea-

\footnotetext{
Correspondence: Rong-chang Chen MD, State Key Lab of Respiratory Disease, Guangzhou Institute of Respiratory Disease, First Affiliated Hospital of Guangzhou Medical University, 151 Yanjiang Road, Guangzhou 510120, Guangdong, People's Republic of China. E-mail: chenrc_1234@163.com; chenrc@vip.163.com.
}

DOI: $10.4187 /$ respcare. 02553 
suring maximum static inspiratory mouth pressure $\left(\mathrm{P}_{\mathrm{I}_{\max }}\right)$ is a simple and widely used method for assessing inspiratory muscle strength, ${ }^{3,4}$ but this technique is relatively difficult to perform and is subjective. ${ }^{5}$ An alternative method for measuring inspiratory muscle strength involves asking the subject to perform short sniffs at maximal intensity, and sniff nasal inspiratory pressure (SNIP) has been described in COPD patients. ${ }^{6}$ The SNIP maneuver is natural and probably easier to perform than the static effort required by $\mathrm{P}_{\mathrm{I}_{\max }}$; nevertheless, the technique still depends on the cooperation of the subject. The nonvolitional technique of twitch transdiaphragmatic pressure in response to phrenic nerve stimulation has been described, ${ }^{7}$ and has been used to determine inspiratory muscle weakness. ${ }^{8}$ This test enables the more accurate assessment of inspiratory muscle contractility, ${ }^{9}$ but is invasive because it requires the placement of esophageal and gastric balloon catheters. Thus, another alternative method, mouth pressure in response to magnetic stimulation of the phrenic nerves $\left(\mathrm{P}_{\mathrm{tw}, \mathrm{m}}\right)$, has been explored, which provides a simple, noninvasive, and objective method for assessing inspiratory muscle strength. ${ }^{10,11}$ However, studies on $\mathrm{P}_{\mathrm{tw}, \mathrm{m}}$ values and their relationship with disease severity in COPD are limited. The body mass index (BMI), air flow obstruction, dyspnea, and exercise capacity (BODE) index is a multidimensional COPD index that has been proven superior to $\mathrm{FEV}_{1}$ in predicting the risk of death of patients, which can reflect the overall severity of the disease. Therefore, the present study aims to test the $\mathrm{P}_{\mathrm{tw}, \mathrm{m}}$ of patients with COPD and to investigate the relationship of their BODE indices with their exercise capacity.

\section{Methods}

The study protocol was approved by the Guangzhou Medical University ethics committee for human investigation (medical ethic 2011-12). Participants provided their written informed consent for the study.

\section{Study Subjects}

The subjects consisted of 75 patients with a clinical diagnosis of COPD according to the Global Initiative for Chronic Obstructive Lung Disease (GOLD) guidelines ${ }^{12}$ and 63 age-matched control subjects (the participants ranged from 50 to $78 \mathrm{y}$ ). All participants underwent a clinical evaluation and were screened using pulmonary function tests. Patients with COPD were recruited from the out-patient clinics of the State Key Laboratory of Respiratory Disease, Guangzhou Institute of Respiratory Disease, First Affiliated Hospital of Guangzhou Medical University, Guangzhou, Guangdong, People's Republic of China. The inclusion criteria were as follows: patients who had spirometry-based diagnosis of COPD, who were pre-

\section{QUICK LOOK}

\section{Current knowledge}

Patients with COPD have reduced respiratory muscle strength owing to dynamic hyperinflation and malnutrition. Twitch mouth pressure $\left(\mathrm{P}_{\mathrm{tw}, \mathrm{m}}\right)$ in response to magnetic stimulation of the cervical nerve has been suggested as a surrogate for measuring inspiratory muscle strength.

\section{What this paper contributes to our knowledge}

$\mathrm{P}_{\mathrm{tw}, \mathrm{m}}$ values were $25 \%$ lower in subjects with COPD compared with the controls. $\mathrm{P}_{\mathrm{tw}, \mathrm{m}}$ values in subjects with COPD decreased with increasing disease severity and were better correlated with the BODE (body mass index, air-flow obstruction, dyspnea, exercise capacity) index and exercise capacity compared with sniff nasal pressure (SNIP) and maximum static inspiratory mouth pressure $\mathrm{P}_{\mathrm{I}_{\max }}$

vious smokers who had abstained from smoking for at least $3 \mathrm{y}$, and who were in stable condition for at least 3 months. The exclusion criteria were as follows: patients who were unwilling to participate or sign informed consent, or patients with major comorbidities or concomitant diseases that might alter muscle function. These comorbidities included neuromuscular disease, uncontrolled diabetes, thyroid disease, and cancer; some comorbidities such as osteoporosis and mild to moderate essential hypertension were not excluded from the study because these comorbidities had no effect on respiratory muscle strength. The control group was recruited from the regular check-up department in the same hospital. The criteria for inclusion in control group were as follows: subjects with normal spirometry, who were nonsmokers or who had abstained from smoking for $>10 \mathrm{y}$, and who had no history of medical illness at the time of the study. In addition, all subjects were assessed by an otorhinolaryngologist to exclude those with nasal septal deviation or rhinitis from the sample. This measure was adopted to ensure that the results of the sniff test were reliable.

The medical treatment of the patients at the time of the study mainly included inhaled bronchodilator therapy in the form of long-acting beta agonists and/or anti-cholinergic agents. In addition, $85 \%$ of the patients were on inhaled corticosteroids (400-800 $\mu \mathrm{g}$ of budesonide equivalent dose/d). None of the patients was on regular systemic corticosteroids. 


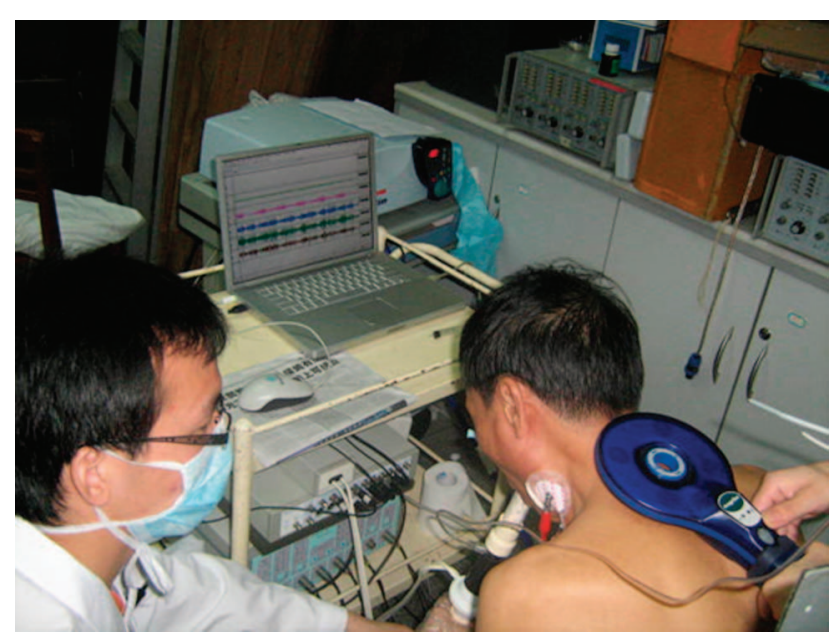

Fig. 1. Photograph of nonvolitional tests for assessing inspiratory muscle strength; the subject was seated, with the neck flexed at approximately $60^{\circ}$ from the vertical when the magnetic stimulation of the cervical nerve was performed.

\section{Testing Methods}

Nonvolitional Test. A nonvolitional test for assessing inspiratory muscle strength was conducted by measuring $\mathrm{P}_{\mathrm{tw}, \mathrm{m}}$ in response to magnetic stimulation of the cervical nerve, which was performed based on the method described in a previous study. ${ }^{11}$ The subjects were seated, with the neck flexed at approximately $60^{\circ}$ from the vertical, wearing a nose clip, and breathing gently through a conventional mouthpiece. During all measurements, breathing frequency and air flow were continuously monitored and plotted on a computer screen. The magnetic stimulation was performed manually using a nonresistant occlusion flow device. To prevent glottal closure, magnetic stimulation was performed at the functional residual capacity under gentle inspiratory effort against the occluded airway with a small leak, and the inspiratory pressure trigger was approximately $-0.5 \mathrm{kPa}$, according to previous studies. ${ }^{10,13}$ The phrenic nerve roots were stimulated using a cervical magnetic stimulator with a circular $90 \mathrm{~mm}$ coil (Magstim 2002, Magstim, Dyfed, Wales, United Kingdom). The coil was placed over the spinous process of the $\mathrm{C} 7$ vertebra and then moved up and down the cervical spine along the midline until the maximum response was obtained at $80 \%$ power output. Thereafter, all stimulations were performed at the same position and at full magnetic output. The stimulations were performed $30 \mathrm{~s}$ apart to avoid twitch potentiation. Figure 1 is a photograph of a study participant during magnetic stimulation.

Mouth pressure was assessed using a differential water pressure transducer (range $\pm 150 \mathrm{~cm} \mathrm{H}_{2} \mathrm{O}$ ). The output signals of mouth pressure and the surface electromyograph of the respiratory muscles were recorded using a Powerlab 8/16SP analog-digital instrument (National Instruments,
Austin, Texas) and a personal computer (Apple, Cupertino, California) running Chart 5.1 software. The measurements were repeated at least 5 times, and the pressure tracings were visible to the operator until 3 satisfactory stimulations were obtained. The mean $\mathrm{P}_{\mathrm{tw}, \mathrm{m}}$ of 3 attempts was chosen for data analysis.

Volitional Tests. Volitional tests consisting of $\mathrm{P}_{\mathrm{I}_{\max }}$ and SNIP assessments were performed on seated subjects, based on standard methods. ${ }^{14}$ The $\mathrm{P}_{\mathrm{I}_{\max }}$ was measured as the lowest pressure sustained for $1 \mathrm{~s}$ during a maximum inspiratory effort from residual volume. ${ }^{14,15}$ The subjects were instructed to breathe through the mouthpiece while wearing a nose clip. During the maneuver, the computer screen was visible to both the subject and monitor, and the subject was encouraged verbally with simultaneous visual feedback on the monitor. Every subject performed each measure at least 5 times until 3 acceptable and reproducible results were obtained, that is, with no leakage and with a $<10 \%$ difference between measurements. ${ }^{16}$

The SNIP test was performed by placing a nasal plug in 1 nostril (no preference for right or left) while keeping the contralateral nostril patent. ${ }^{17,18}$ The subjects were instructed to perform short sharp sniffs with a closed mouth, starting from functional residual capacity after a quiet breath. They were asked to breathe normally with a closed mouth and to perform 10 maximal, short, and sharp sniffs at 30-s intervals. The functional residual capacity was not controlled but was identified as the end of expiration during quiet breathing. Similarly, the monitor was visible to the subjects, and the sniffs were recorded until no further increase in pressure could be obtained; the highest value was used for analysis. ${ }^{16-18} \mathrm{P}_{\mathrm{tw}, \mathrm{m}}, \mathrm{SNIP}$, and $\mathrm{P}_{\mathrm{I}_{\max }}$ were all expressed as positive values even though they were negative with respect to the atmosphere.

\section{Spirometric Function}

Spirometry was performed by experienced certified technicians at the lung function laboratory in the State Key Laboratory of Respiratory Disease. The lung function equipment met the criteria of the European Respiratory Society. ${ }^{19}$ The height and weight of the subjects were recorded, with the subjects barefooted and wearing indoor clothing. Spirometry was performed on each seated subject using a Microlab 3300 spirometer (Micro Medical, Kent, United Kingdom), according to European Respiratory Society standards. The best value of 3 recordings was used. The FEV ${ }_{1}$ and FVC values are expressed as percentages of the predicted values, adjusted for age, gender, and height. The predicted values were those of the European Community of Coal and Steel approved by the European Respiratory Society. ${ }^{20}$ For subjects with COPD, irreversible air flow obstruction was confirmed using a post-bron- 
chodilator (400 $\mu \mathrm{g}$ of salbutamol) $\mathrm{FEV}_{1} / \mathrm{FVC}<70 \%$. The severity of air flow obstruction was classified according to the GOLD guidelines. ${ }^{12}$

\section{Calculation of BODE Index}

The BODE index was calculated in subjects with COPD using the score proposed by Celli et al. ${ }^{21}$ Dyspnea was assessed according to the modified Medical Research Council scale. ${ }^{22}$ Exercise capacity was evaluated using the 6-min walk distance (6MWD), based on the guidelines of the American Thoracic Society. ${ }^{23}$ The BODE index was calculated for each subject using variables obtained within 4 weeks of enrollment, and the total value for each subject ranged from 0 to 10 , with higher scores indicating more severe disease.

\section{Statistical Analysis}

Statistical analysis was performed using SPSS 12.0 (SPSS, Chicago, Illinois) and GraphPad Prism 5 (GraphPad Software, San Diego, California). Normally distributed data are expressed as means \pm SD. Non-normally distributed data are expressed as medians with ranges in parentheses. The level of statistical significance was set at $P<.05$. Two independent-sample $t$ tests and chi-square test were used for univariate testing between the COPD group and the control group. The differences among the multiple groups (controls and subjects with COPD at different GOLD stages) were tested by analysis of variance, with the least significant difference test for post hoc pairwise comparison. The Pearson correlation coefficient was used to correlate the independent variables (age, weight, height, BMI, and history of smoking) with the dependent variables $\left(\mathrm{P}_{\mathrm{tw}, \mathrm{m}}, \mathrm{SNIP}\right.$, and $\mathrm{P}_{\mathrm{I}_{\max }}$, respectively) in the COPD group. Multiple regression modeling was developed stepwise to determine the dependent relationship of inspiratory muscle strength $\left(\mathrm{P}_{\mathrm{tw}, \mathrm{m}}, \mathrm{SNIP}\right.$, and $\mathrm{P}_{\mathrm{I}_{\max }}$ values) with the BODE index, $\mathrm{FEV}_{1}$ percent predicted, and $6 \mathrm{MWD}$ distance in patients with COPD. The values were adjusted for confounding factors, including age, weight, height, BMI, and history of smoking.

\section{Results}

\section{Characteristics of the Subjects}

No exclusions were imposed for all participants who submitted to the assessments. The characteristics of the study subjects are detailed in Table 1 . The gender constituent ratio differed significantly between the 2 groups. The 2 groups were matched in terms of age and height, but differences were observed for weight, BMI, inspiratory muscle strength, and history of smoking. The median num-
Table 1. General Characteristics of Study Participants

\begin{tabular}{|c|c|c|c|c|}
\hline Characteristics & $\begin{array}{l}\text { Control } \\
\text { Subjects } \\
(n=63)\end{array}$ & $\begin{array}{l}\text { Subjects } \\
\text { with COPD } \\
(n=75)\end{array}$ & Statistics & $P$ \\
\hline Male, $n(\%)$ & $40(63)$ & $63(84)$ & $21.05^{*}$ & $<.01$ \\
\hline Age, mean $\pm S D, y$ & $64.01 \pm 7.01$ & $64.43 \pm 7.91$ & $0.73 \dagger$ & .47 \\
\hline $\begin{array}{l}\text { Height, mean } \pm \mathrm{SD} \text {, } \\
\mathrm{cm}\end{array}$ & $160.2 \pm 6.24$ & $162.85 \pm 6.3$ & $0.15 \dagger$ & .88 \\
\hline $\begin{array}{l}\text { Weight, mean } \pm \mathrm{SD} \text {, } \\
\mathrm{kg}\end{array}$ & $63.34 \pm 9.33$ & $53.29 \pm 8.53$ & $6.55 \dagger$ & $<.001$ \\
\hline $\begin{array}{l}\mathrm{BMI}, \text { mean } \pm \mathrm{SD} \text {, } \\
\mathrm{kg} / \mathrm{m}^{2}\end{array}$ & $23.79 \pm 2.90$ & $20.08 \pm 2.89$ & $7.49 \dagger$ & $<.001$ \\
\hline $\begin{array}{c}\mathrm{FEV}_{1} \% \text { predicted, } \\
\text { mean } \pm \mathrm{SD}\end{array}$ & $96.13 \pm 9.78$ & $38.99 \pm 14.01$ & $27.25 \dagger$ & $<.001$ \\
\hline $\begin{array}{l}\mathrm{FEV}_{1} / \mathrm{FVC} \\
\text { mean } \pm \mathrm{SD}\end{array}$ & $0.82 \pm 0.08$ & $0.43 \pm 0.012$ & $22.40 \dagger$ & $<.00$ \\
\hline $\begin{array}{c}\text { FVC } \% \text { predicted, } \\
\text { mean } \pm \mathrm{SD}\end{array}$ & $95.20 \pm 12.07$ & $72.04 \pm 16.76$ & $9.27 \dagger$ & $<.001$ \\
\hline Exsmokers, $n(\%)$ & $12(19)$ & $57(76)$ & $44.42 *$ & $<.00$ \\
\hline $\begin{array}{l}\text { * Chi-square value } \\
\dagger t \text { values. } \\
\text { BMI = body mass index }\end{array}$ & & & & \\
\hline
\end{tabular}

ber of pack-years for previous smokers was $0(0-7)$ packyears for the controls and $20(0-35)$ pack-years for the patients with COPD.

Pulmonary function test showed that subjects with COPD exhibited severely obstructed air flow, as defined by the GOLD criteria, with $\mathrm{FEV}_{1}<50 \%$ predicted. The subjects were stratified for disease severity based on GOLD guidelines as follows: stage II, 16 (14 male and 2 female) subjects; stage III, 32 (26 male and 6 female) subjects; and stage IV, 27 (23 male and 4 female) subjects.

\section{Muscle Strength}

Figure 2 shows a typical example of the $\mathrm{P}_{\mathrm{tw}, \mathrm{m}}$ recordings during magnetic stimulation of the cervical nerves in the healthy controls. The mean $\mathrm{P}_{\mathrm{tw}, \mathrm{m}}$ was significantly lower in subjects with COPD than the controls $(10.00 \pm 2.17$ vs $13.66 \pm 2.20 \mathrm{~cm} \mathrm{H}_{2} \mathrm{O}$ for males $[P<.001]$, and $8.83 \pm 0.89$ vs $11.81 \pm 1.98 \mathrm{~cm} \mathrm{H}_{2} \mathrm{O}$ for females $[P<.001])$. When stratified for disease severity based on the GOLD guidelines, $P_{t w, m}$ decreased with increasing COPD severity, and the SNIP and $\mathrm{P}_{\mathrm{I}_{\max }}$ values exhibited similar trends (Table 2). Figure 3A shows the differences in $\mathrm{P}_{\mathrm{tw}, \mathrm{m}}$ between the subjects with COPD and the controls when stratified for gender. Figure $3 \mathrm{~B}$ shows the differences in $\mathrm{P}_{\mathrm{tw}, \mathrm{m}}$ among the 4 subgroups (male controls, and male subjects with COPD at GOLD stages II, III, and IV).

\section{BODE Index}

Table 3 shows the results of the variables used to compute the BODE index of subjects with COPD, with strat- 

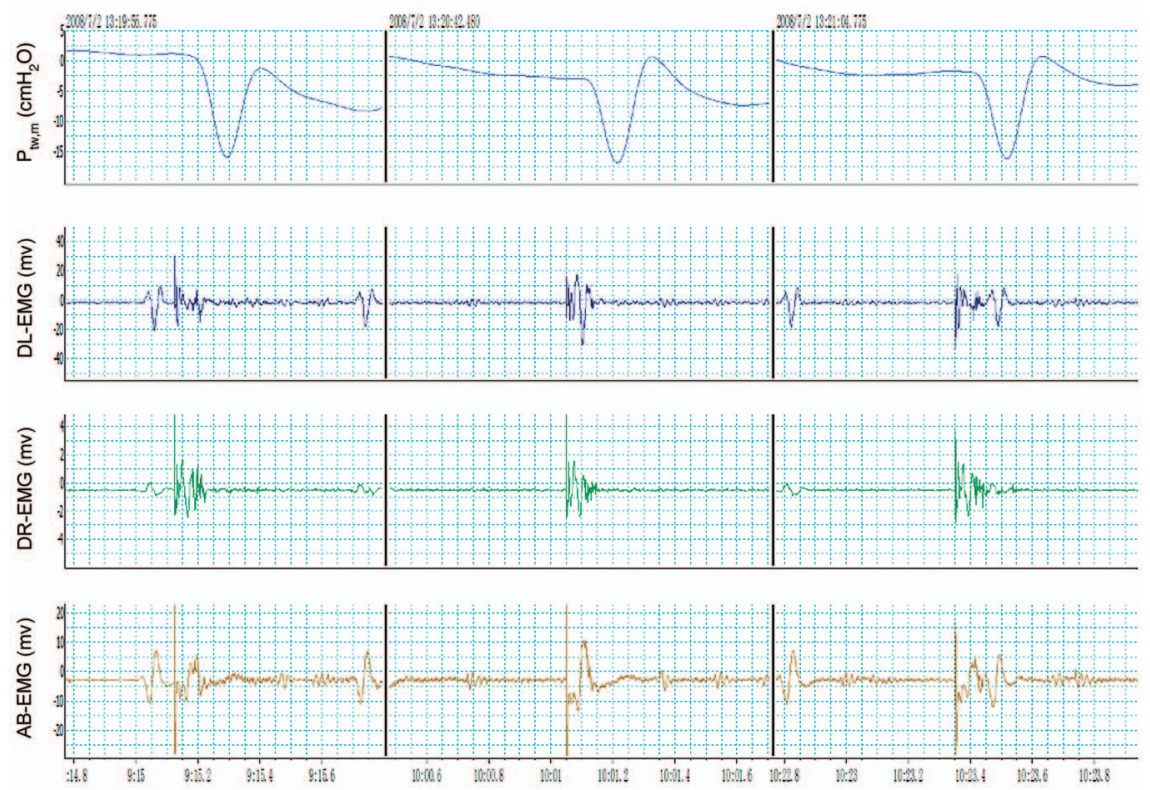

Fig. 2. Simultaneous force and surface electromyography recordings during twitch mouth pressure $\left(P_{t w, m}\right)$ tests. The lines on the top channel represent 3 consecutive $P_{t w, m}$ values; surface electromyography signals from respiratory muscles are shown on channels 2 , 3 , and 4. The mean $\mathrm{P}_{\mathrm{tw}, \mathrm{m}}$ was approximately $17.5 \mathrm{~cm} \mathrm{H}_{2} \mathrm{O}$ in this normal male subject.

Table 2. Inspiratory Muscle Function

\begin{tabular}{|c|c|c|c|c|c|}
\hline \multirow{2}{*}{ Variables } & \multirow{2}{*}{$\begin{array}{l}\text { Control } \\
\text { Subjects }\end{array}$} & \multicolumn{3}{|c|}{ Subjects with COPD } & \multirow{2}{*}{$P$} \\
\hline & & Stage II & Stage III & Stage IV & \\
\hline Subjects, $n$ (male/female) & $63(40 / 23)$ & $16(12 / 2)$ & $32(26 / 6)$ & $27(23 / 4)$ & $<.01$ \\
\hline \multicolumn{6}{|l|}{$\mathrm{P}_{\mathrm{tw}, \mathrm{m}}$, mean $\pm \mathrm{SD}, \mathrm{cm} \mathrm{H}_{2} \mathrm{O}$} \\
\hline Male & $13.66 \pm 2.20$ & $11.89 \pm 2.41$ & $10.51 \pm 1.61$ & $8.18 \pm 1.14$ & $<.001$ \\
\hline Female & $11.81 \pm 1.98$ & $9.86 \pm 0.76$ & $8.88 \pm 0.74$ & $8.24 \pm 0.51$ & $<.001$ \\
\hline \multicolumn{6}{|l|}{$\mathrm{SNIP}$, mean $\pm \mathrm{SD}, \mathrm{cm} \mathrm{H}_{2} \mathrm{O}$} \\
\hline Male & $103.17 \pm 14.62$ & $99.78 \pm 14.14$ & $85.78 \pm 10.48$ & $78.47 \pm 7.29$ & $<.001$ \\
\hline Female & $89.45 \pm 11.48$ & $76.81 \pm 3.90$ & $70.01 \pm 4.08$ & $63.61 \pm 3.44$ & $<.001$ \\
\hline \multicolumn{6}{|l|}{$\mathrm{P}_{\mathrm{I}_{\max }}$, mean $\pm \mathrm{SD}, \mathrm{cm} \mathrm{H}_{2} \mathrm{O}$} \\
\hline Male & $97.03 \pm 15.51$ & $76.26 \pm 8.16$ & $71.56 \pm 8.68$ & $65.64 \pm 8.20$ & $<.001$ \\
\hline Female & $83.10 \pm 8.25$ & $65.80 \pm 4.82$ & $64.06 \pm 6.45$ & $63.72 \pm 6.76$ & $<.001$ \\
\hline $\begin{array}{l}\mathrm{P}_{\mathrm{tw}, \mathrm{m}}=\text { twitch mouth } \\
\mathrm{SNIP}=\text { sniff pressure } \\
\mathrm{P}_{\mathrm{I}_{\max }}=\text { maximum inspiratory pressure }\end{array}$ & & & & & \\
\hline
\end{tabular}

ification for the severity distribution based on the GOLD guidelines.

\section{Correlations}

The Pearson correlation analysis showed that the $\mathrm{P}_{\mathrm{tw}, \mathrm{m}}$ values of subjects with COPD were significantly correlated with age $(\mathrm{r}=-0.24, P=.04)$ and $\mathrm{BMI}(\mathrm{r}=0.26$, $P=.02)$, but not with height ( $\mathrm{r}=0.17, P=.16)$, weight ( $\mathrm{r}=0.12, P=.29)$, or history of smoking $(\mathrm{r}=-0.14$, $P=.22)$. SNIP was slightly correlated with BMI $(\mathrm{r}=0.23$,
$P=.049)$, but not with age $(\mathrm{r}=-0.11, P=.34)$, height (r $=0.23, P=.05)$, or weight $(\mathrm{r}=0.23, P=.049)$. None of the parameters was significantly correlated with the $\mathrm{P}_{\mathrm{I}_{\max }}$ of the subjects with COPD ( $P>.05$ for each).

Adjusting for the confounding factors, multiple regression analysis showed that $\mathrm{P}_{\mathrm{tw}, \mathrm{m}}$ was moderately correlated inversely with the BODE index $\left(\mathrm{R}^{2}=0.46, P<.001\right)$ (Table 4), but positively correlated with 6MWD and $\mathrm{FEV}_{1}$ percent predicted (each $P<.05$ ). Similar results were also observed for SNIP, but with lower $\mathrm{R}$ values (Table 5). The $\mathrm{P}_{\mathrm{I}_{\max }}$ values were slightly correlated with 
A

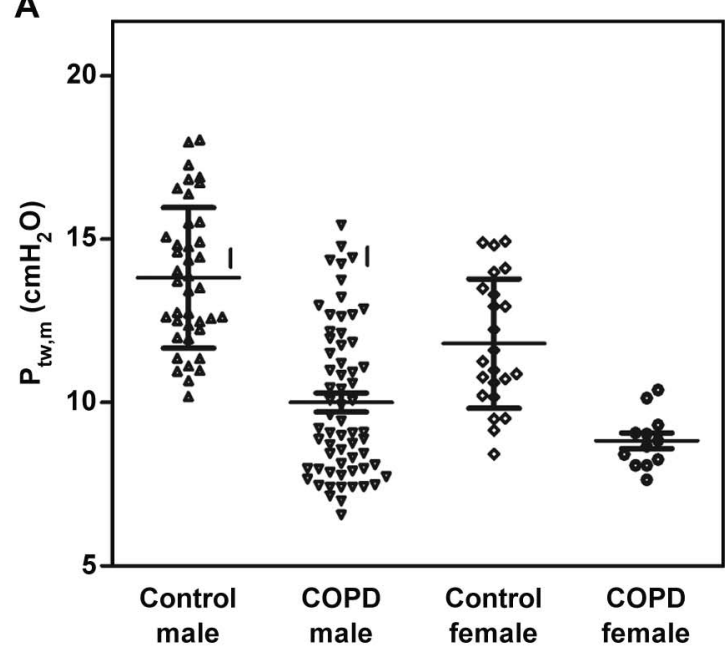

B

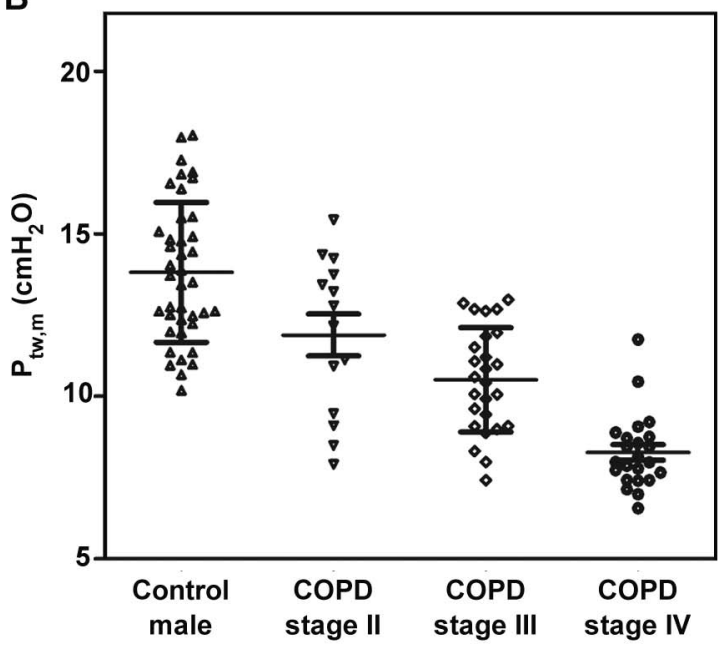

Fig. 3. Analysis (mean $\pm S D$ ) of the $P_{t w, m}$ values. A: subjects with COPD had significantly lower $P_{t w, m}$ values compared with the controls among both males and females. B: subjects with COPD had lower $P_{t w, m}$ values than the control, and they decreased with increasing Global Initiative for Chronic Obstructive Lung Disease (GOLD) stage among male subjects.

Table 3. BODE Index and Functional Parameters of COPD Subjects

\begin{tabular}{|c|c|c|c|}
\hline \multirow{2}{*}{ Characteristics } & \multicolumn{3}{|c|}{ Subjects with COPD } \\
\hline & Stage II & Stage III & Stage IV \\
\hline Subjects, $n(\%)$ & $16(21)$ & $32(43)$ & $27(36)$ \\
\hline $\begin{array}{l}\mathrm{BMI}, \text { mean } \pm \mathrm{SD}, \\
\mathrm{kg} / \mathrm{m}^{2}\end{array}$ & $20.18 \pm 3.14$ & $20.90 \pm 2.91$ & $19.05 \pm 2.49$ \\
\hline $\begin{array}{c}\mathrm{FEV}_{1} \% \text { predicted } \\
\text { mean } \pm \mathrm{SD}\end{array}$ & $59.67 \pm 5.69$ & $41.23 \pm 6.33$ & $24.49 \pm 4.45$ \\
\hline $\begin{array}{c}\text { MMRC dyspnea scale } \\
\text { score, mean } \pm \text { SD }\end{array}$ & $1.00 \pm 0.63$ & $1.87 \pm 0.75$ & $3.22 \pm 0.75$ \\
\hline $\begin{array}{l}\text { 6MWD, } \\
\text { mean } \pm \mathrm{SD}, \mathrm{m}\end{array}$ & $401.88 \pm 70.15$ & $355.63 \pm 49.01$ & $264.81 \pm 64.20$ \\
\hline $\begin{array}{l}\text { BODE index score, } \\
\text { mean } \pm \mathrm{SD}\end{array}$ & $2.25 \pm 1.29$ & $4.51 \pm 1.67$ & $7.74 \pm 1.43$ \\
\hline \multicolumn{4}{|c|}{$\begin{array}{l}\text { BMI }=\text { body mass index } \\
\text { MMRC = Modified Medical Research Council } \\
\text { 6MWD }=6 \text {-min walk distance } \\
\text { BODE = body mass index, air-flow obstruction, dyspnea, exercise capacity }\end{array}$} \\
\hline
\end{tabular}

these variables, with $\mathrm{R}$ values significantly lower than those for SNIP. Table 5 shows the correlation coefficients of inspiratory muscle strength $\left(\mathrm{P}_{\mathrm{tw}, \mathrm{m}}, \mathrm{SNIP}\right.$, and $\left.\mathrm{P}_{\mathrm{I}_{\max }}\right)$ with the clinical parameters of COPD.

\section{Discussion}

The present cross-sectional study investigated the differences in inspiratory muscle strength between subjects with COPD and age-matched controls using both volitional (SNIP and $\mathrm{P}_{\mathrm{I}_{\max }}$ ) and nonvolitional $\left(\mathrm{P}_{\mathrm{tw}, \mathrm{m}}\right)$ techniques. To our knowledge, this is the first study to describe separately the $\mathrm{P}_{\mathrm{tw}, \mathrm{m}}$ of male and female subjects with COPD
Table 4. Correlation of BODE Index With Twitch Mouth Pressure and Adjustment for Confounding Factor

\begin{tabular}{lcccc}
\hline \hline & & \multicolumn{2}{c}{ Standard } & \\
\cline { 3 - 4 } & Unstandardized, B & \multicolumn{2}{c}{$P$} & $P$ \\
\hline Constant & 16.494 & & 1.564 & $<.001$ \\
BODE index & -0.517 & -0.647 & 0.068 & $<.001$ \\
Age & -0.063 & -0.225 & 0.024 & .01
\end{tabular}

BODE = body mass index, air-flow obstruction, dyspnea, exercise capacity

Table 5. Correlation Coefficients (R Values) of Inspiratory Muscle Strength With Clinical Parameters

\begin{tabular}{lcccccc}
\hline \hline & $\begin{array}{c}\mathrm{P}_{\mathrm{tw}, \mathrm{m}} \\
\text { Correlation }\end{array}$ & $P$ & $\begin{array}{c}\text { SNIP } \\
\text { Correlation }\end{array}$ & $P$ & $\begin{array}{c}\mathrm{P}_{\mathrm{I}_{\max }} \\
\text { Correlation }\end{array}$ & $P$ \\
\hline $\begin{array}{c}\mathrm{FEV}_{1} \% \\
\text { predicted }\end{array}$ & 0.629 & $<.001$ & 0.35 & .002 & 0.253 & .03 \\
$\begin{array}{l}\text { 6MWD } \\
\text { BODE index }\end{array}$ & 0.593 & $<.001$ & 0.33 & .003 & 0.277 & .02 \\
& 0.652 & $<.001$ & 0.49 & $<.001$ & 0.265 & .02
\end{tabular}

$\mathrm{P}_{\mathrm{tw}, \mathrm{m}}=$ twitch mouth pressure

SNIP $=$ sniff pressure

$\mathrm{P}_{\mathrm{I}}=$ maximum inspiratory pressure

$6 \mathrm{MWD}=6-\mathrm{min}$ walk distance

BODE $=$ body mass index, air-flow obstruction, dyspnea, exercise capacity

and the relationship of $\mathrm{P}_{\mathrm{tw}, \mathrm{m}}$ with the BODE index in COPD. The principal findings are summarized as follows. $\mathrm{P}_{\mathrm{tw}, \mathrm{m}}$ markedly decreased with increasing disease severity among subjects with moderate to very severe COPD, similarly to SNIP and $\mathrm{P}_{\mathrm{I}_{\max }}$. $\mathrm{P}_{\mathrm{tw}, \mathrm{m}}$ was better correlated with the BODE index and exercise capacity than were SNIP and $\mathrm{P}_{\mathrm{I}_{\max }}$, which suggests that $\mathrm{P}_{\mathrm{tw}, \mathrm{m}}$ more accurately re- 
flects the overall severity of COPD than does SNIP and $\mathrm{P}_{\mathrm{I}_{\max }}$.

All of the subjects tolerated both the volitional (SNIP and $\left.\mathrm{P}_{\mathrm{I}_{\max }}\right)$ and nonvolitional $\left(\mathrm{P}_{\mathrm{tw}, \mathrm{m}}\right)$ techniques. $\mathrm{P}_{\mathrm{tw}, \mathrm{m}}$, SNIP, and $\mathrm{P}_{\mathrm{I}_{\max }}$ were all significantly decreased among subjects relative to controls. The result shows that all 3 techniques are suitable for clinically assessing inspiratory muscle strength in patients with moderate to very severe COPD. However, $P_{I_{\max }}$ was more difficult for subjects than $P_{t w, m}$ and SNIP. When we analyzed the $\mathrm{P}_{\mathrm{I}_{\max }}$ values, it was necessary to consider the difficulty of subjects in performing maximal effort, because this test is highly dependent on both their effort and instructions of individual technologists. ${ }^{24}$ Moreover, achieving the quality goal does not necessarily mean that the subject exerted maximal effort. ${ }^{25}$ SNIP was easier to perform and less unpleasant for each subject than the $\mathrm{P}_{\mathrm{I}_{\max }}$ test, which is consistent with previous studies. ${ }^{16,26}$ This finding confirms that SNIP could be used as an alternative or as a complement to $\mathrm{P}_{\mathrm{I}_{\max }}$ measurement. ${ }^{27}$ Nevertheless, SNIP also depends on volitional muscle contraction.

In contrast to the volitional tests $\mathrm{P}_{\mathrm{I}_{\max }}$ and SNIP, $\mathrm{P}_{\mathrm{tw}, \mathrm{m}}$ is an objective measurement independent of the instructions of the technologists and the learning curves and cooperation of subjects. Moreover, cervical magnetic stimulation was well tolerated by the subjects, and it facilitated the repeated measurement of inspiratory muscle contractility. These findings are consistent with those of previous studies. ${ }^{10,11,28}$ In addition, $\mathrm{P}_{\mathrm{tw}, \mathrm{m}}$ values are reportedly reproducible $^{14}$ and highly correlated with the twitch transdiaphragmatic pressures under the same stimulation conditions, ${ }^{11,28,29}$ which indicates that $\mathrm{P}_{\mathrm{tw}, \mathrm{m}}$ values accurately reflect inspiratory muscle strength. Nonetheless, $\mathrm{P}_{\mathrm{tw}, \mathrm{m}}$ test is noninvasive, unlike twitch transdiaphragmatic pressure. These points suggest that the $\mathrm{P}_{\mathrm{tw}, \mathrm{m}}$ test is sufficiently valid and more suitable than the other tests for clinically assessing inspiratory muscle strength. Moreover, magnetic stimulation of the cervical nerve is simple and easy to apply, and the instrumentation is relatively easy for technologists and for subjects. The advantages of the $\mathrm{P}_{\mathrm{tw}, \mathrm{m}}$ test over volitional tests suggest that $\mathrm{P}_{\mathrm{tw}, \mathrm{m}}$ is a potential routine test for all hospital departments, especially ICUs. For example, the $\mathrm{P}_{\mathrm{tw}, \mathrm{m}}$ test is ideal for evaluating the inspiratory muscle strength of patients with COPD to be weaned from mechanical ventilation support. Moreover, the $\mathrm{P}_{\mathrm{tw}, \mathrm{m}}$ test could be better than volitional tests for evaluating the inspiratory muscle strength of patients with muscular disease or those dependent on mechanical ventilation.

The mean $\mathrm{P}_{\mathrm{tw}, \mathrm{m}}$ values were $26.8 \%$ lower in male subjects with COPD and $25.3 \%$ lower in female subjects with COPD compared with the controls. Our data suggest that inspiratory muscle strength of patients with COPD is substantially impaired, regardless of gender. Expiratory flow obstruction and a concomitant increase in inspiratory work cause respiratory muscle weakness among patients with COPD. ${ }^{31}$ Consistently, the present data show that $P_{t w, m}$ values were markedly decreased in patients with moderate to very severe COPD, which indicates that impaired inspiratory muscle strength of COPD is associated with air flow limitation. A variety of factors can compromise inspiratory muscle function in COPD. These factors may be classified into local mechanical changes and systemic pathophysiologic changes. The diaphragm always works in an unfavorable position under air flow limitation and hyperinflation, which decreases the inspiratory muscle capacity and compromises inspiratory muscle function through overloading of the intrinsic PEEP and hyperinflation. ${ }^{32,33}$ Consistent with these studies, our $\mathrm{P}_{\mathrm{tw}, \mathrm{m}}$ values were significantly correlated with the $\mathrm{FEV}_{1}$ percent predicted of patients with COPD, which was also reported by Kabitz et al..$^{30}$ Thus, decreased inspiratory muscle strength is at least partly attributed to the air flow limitation of COPD. However, air flow limitation and hyperinflation do not fully explain the impairment of inspiratory muscle strength, as systemic pathophysiologic changes also serve important functions in respiratory muscle dysfunction. These systemic changes include systemic inflammation, ${ }^{34}$ hypoxemia and related oxidative stress and myopathy, 35,36 undernutrition, ${ }^{37}$ endocrine disturbances, ${ }^{38}$ and remodeling of respiratory muscles. ${ }^{39}$

Our data show that subjects with COPD have markedly decreased 6MWD relative to the controls, which is reportedly associated with dyspnea and/or lower limb muscle fatigue. Our data are consistent with a study that associated impaired skeletal muscle endurance with the physical inactivity and altered lung function of patients with COPD. ${ }^{40}$ Patients with COPD often experience a downward spiral of symptom-induced inactivity that leads to peripheral muscle weakness, especially of lower limb muscles. ${ }^{41,42}$ Consistent with these study results, our study shows that decreased 6MWD is significantly correlated with the $\mathrm{P}_{\mathrm{tw}, \mathrm{m}}$ values in COPD. 6MWD, a global marker for functional capacity in the cardiorespiratory domain, integrates diverse physiologic components. ${ }^{43}$ Moreover, 6MWD is suitable for predicting the survival of patients with COPD. ${ }^{44}$ Collectively, our results suggest that decreased $\mathrm{P}_{\mathrm{tw}, \mathrm{m}}$ indicate impaired inspiratory muscle strength, as well as decreased exercise capacity in COPD.

$\mathrm{P}_{\mathrm{tw}, \mathrm{m}}$ values were significantly correlated inversely with the BODE index of COPD, which indicates that these COPD indices have complex interactions. Kabitz et al ${ }^{30}$ found that $\mathrm{P}_{\mathrm{tw}, \mathrm{m}}$ values are correlated with both $\mathrm{FEV}_{1}$ percent predicted and 6MWD in COPD, but they did not investigate the relationship between $\mathrm{P}_{\mathrm{tw}, \mathrm{m}}$ values and the BODE index. The BODE index is an important multidimensional index for the severity of COPD that incorporates 4 independent predictors of survival ${ }^{45}$; $6 \mathrm{MWD}$ and 
$\mathrm{FEV}_{1}$ percent predicted are 2 of the 4 clinically functional parameters. Considering COPD is multidimensional, the BODE classification scheme, which incorporates more parameters, is likely to predict more accurate outcomes. ${ }^{46}$ The BODE index has been proven to correspond to important differences in the health status of patients with COPD ${ }^{47}$ Therefore, the inverse correlation between $\mathrm{P}_{\mathrm{tw}, \mathrm{m}}$ values and the BODE index suggests that decreased inspiratory muscle function imposes a substantial burden on patients with COPD and reflects their poor health status.

The current study has several limitations. First, no preference for the occluded nostril was considered in our study. Thus, although patients with nasal septal deviation and rhinitis were excluded, we are uncertain whether the methodology influenced the standardization of the procedure. Second, few female subjects with COPD were included in the study; thus, the conclusions should be confirmed using additional studies with more female subjects, although the limited female population in this study is sufficient for understanding the inspiratory muscle strength of patients with COPD. Third, the predicted values for spirometric function were calculated based on the European Respiratory Society standards; using a specific reference value based on the regression of a large sample population of healthy Chinese would be more helpful.

\section{Conclusions}

In conclusion, $\mathrm{P}_{\mathrm{tw}, \mathrm{m}}$ values are $26.8 \%$ lower in male subjects with COPD and $25.3 \%$ lower in female subjects with COPD compared with the controls. The $\mathrm{P}_{\mathrm{tw}, \mathrm{m}}$ values of subjects with COPD decrease with increasing disease severity. The better correlations of $P_{t w, m}$ values with the BODE index and exercise capacity compared with those of SNIP and $\mathrm{P}_{\mathrm{I}_{\max }}$ suggest that $\mathrm{P}_{\mathrm{tw}, \mathrm{m}}$ more accurately reflects the overall severity and burden of COPD.

\section{ACKNOWLEDGMENTS}

We thank all the participants in the study. We also thank Mei Jiang for her help in the statistical analysis. We thank all of our colleagues for their support and cooperation in making this work a success.

\section{REFERENCES}

1. van der Palen J, Rea TD, Manolio TA, Lumley T, Newman AB, Tracy RP. Respiratory muscle strength and the risk of incident cardiovascular events. Thorax 2004;59(12):1063-1067.

2. Zielinski J, MacNee W, Wedzicha J, Ambrosino N, Braghiroli A, Dolensky J, et al. Causes of death in patients with COPD and chronic respiratory failure. Monaldi Arch Chest Dis 1997;52(1):43-47.

3. DePalo VA, Parker AL, Al-Bilbeisi F, McCool FD. Respiratory muscle strength training with nonrespiratory maneuvers. J Appl Physiol 2004;96(2):731-734.

4. Bild DE, Bluemke DA, Burke GL, Detrano R, Diez Roux AV, Folsom AR, et al. Multi-ethnic study of atherosclerosis: objectives and design. Am J Epidemiol 2002;156(9):871-881.
5. McConnell AK, Copestake AJ. Maximum static respiratory pressures in healthy elderly men and women: issues of reproducibility and interpretation. Respiration 1999;66(3):251-258.

6. Martínez-Llorens J, Ausín P, Roig A, Balañá A, Admetlló M, Muñoz L, Gea J. Nasal inspiratory pressure: an alternative for the assessment of inspiratory muscle strength? Arch Bronconeumol 2011;47(4): 169-175.

7. Hamnegård CH, Wragg SD, Mills GH, Kyroussis D, Polkey MI, Bake B, et al. Clinical assessment of diaphragm strength by cervical magnetic stimulation of the phrenic nerves. Thorax 1996;51(12): 1239-1242.

8. Hughes PD, Polkey MI, Kyroussis D, Hamnegard CH, Moxham J, Green M. Measurement of sniff nasal and diaphragm twitch mouth pressure in patients. Thorax 1998;53(2):96-100.

9. Man WD, Moxham J, Polkey MI. Magnetic stimulation for the measurement of respiratory and skeletal muscle function. Eur Respir $\mathbf{J}$ 2004;24(5):846-860.

10. Windisch W, Kabitz HJ, Sorichter S. Influence of different trigger techniques on twitch mouth pressure during bilateral anterior magnetic phrenic nerve stimulation. Chest 2005;128(1):190-195.

11. Jonville S, Delpech N, Denjean A. Contribution of respiratory acidosis to diaphragmatic fatigue at exercise. Eur Respir J 2002;19(6): 1079-1086.

12. Global Initiative for Chronic Obstructive Lung Disease. Global strategy for the diagnosis, management and prevention of chronic obstructive pulmonary disease (revised 2011). http://www.goldcopd. org/uploads/users/files/GOLD_Report_2011_Feb21.pdf. Accessed May 20, 2014.

13. Kabitz HJ, Walker D, Walterspacher S, Windisch W. Controlled twitch mouth pressure reliably predicts twitch esophageal pressure. Respir Physiol Neurobiol 2007;156(3):276-282.

14. Maillard JO, Burdet L, van Melle G, Fitting JW. Reproducibility of twitch mouth pressure, sniff nasal inspiratory pressure, and maximal inspiratory pressure. Eur Respir J 1998;11(4):901-905.

15. Freitas FS, Ibiapina CC, Alvim CG, Britto RR, Parreira VF. Relationship between cough strength and functional level in elderly. Rev Bras Fisioter 2010;14(6):470-476.

16. Lofaso F, Nicot F, Lejaille M, Falaize L, Louis A, Clement A, et al. Sniff nasal inspiratory pressure: what is the optimal number of sniffs? Eur Respir J 2006;27(5):980-982.

17. Severino FG, Resqueti VR, Bruno SS, Azevedo IG, Vieira RH, Fregonezi GA. Comparison between a national and a foreign manovacuometer for nasal inspiratory pressure measurement. Rev Bras Fisioter 2010;14(5):426-431.

18. Uldry C, Janssens JP, de Muralt B, Fitting JW. Sniff nasal inspiratory pressure in patients with chronic obstructive pulmonary disease. Eur Respir J 1997;10(6):1292-1296.

19. Miller MR, Hankinson J, Brusasco V, Burgos F, Casaburi R, Coates A, et al. Standardisation of spirometry. Eur Respir J 2005;26(2):319338.

20. Quanjer PH, Tammeling GJ, Cotes JE, Pedersen OF, Peslin R, Jernault JC. Lung volumes and forced ventilatory flows. Report Working Party Standardization of Lung Function Tests, European Community for Steel and Coal. Official statement of the European Respiratory Society. Eur Respir J 1993;16(Suppl):5-40.

21. Celli BR, Cote CG, Marin JM, Casanova C, Montes de Oca M, Mendez RA, et al. The body-mass index, airflow obstruction, dyspnea, and exercise capacity index in chronic obstructive pulmonary disease. N Engl J Med 2004;350(10):1005-1012.

22. Mahler DA, Wells CK. Evaluation of clinical methods for rating dyspnea. Chest 1988;93(3):580-586.

23. ATS Committee on Proficiency Standards for Clinical Pulmonary Function Laboratories. ATS statement: guidelines for the six minute walk test, Am J Respir Crit Care Med 2002;166: 111-117. 


\section{Twitch Mouth Pressure And COPD}

24. Laghi F, Tobin MJ. Disorders of the respiratory muscles. Am J Respir Crit Care Med 2003;168(1):10-48.

25. Aldrich TK, Spiro P. Maximal inspiratory pressure: does reproducibility indicate full effort? Thorax 1995;50(1):40-43.

26. Stefanutti D, Benoist MR, Scheinmann P, Chaussain M, Fitting JW. Usefulness of sniff nasal pressure in patients with neuromuscular or skeletal disorders. Am J Respir Crit Care Med 2000;162(4 Pt 1): 1507-1511.

27. American Thoracic Society/European Respiratory Society. ATS/ERS statement on respiratory muscle testing. Am J Respir Crit Care Med 2002;166(4):518-524.

28. de Bruin PF, Watson RA, Khalil N, Pride NB. Use of mouth pressure twitches induced by cervical magnetic stimulation to assess voluntary activation of the diaphragm. Eur Respir J 1998;12(3):672-678.

29. Laghi F, Tobin MJ. Relationship between transdiaphragmatic and mouth twitch pressures at functional residual capacity. Eur Respir J 1997;10(3):530-536.

30. Kabitz HJ, Walterspacher S, Walker D, Windisch W. Inspiratory muscle strength in chronic obstructive pulmonary disease depending on disease severity. Clin Sci (Lond) 2007;113(5):243-249.

31. Segal E. Intrinsic positive end expiratory pressure (PEEPI) in mechanically ventilated patients. Harefuah 2007;146(10):790-793, 812-813.

32. O'Donnell DE. Hyperinflation, dyspnea, and exercise intolerance in chronic obstructive pulmonary disease. Proc Am Thorac Soc 2006; 3(2): 180-184.

33. Dos Santos Yamaguti WP, Paulin E, Shibao S, Chammas MC, Salge $\mathrm{JM}$, Ribeiro M, et al. The major factor limiting diaphragm mobility in chronic obstructive pulmonary disease patients. Respirology 2008; 13(1):138-144.

34. Gan WQ, Man SF, Senthilselvan A, Sin DD. Association between chronic obstructive pulmonary disease and systemic inflammation: a systematic review and a meta-analysis. Thorax 2004;59(7):574-580.

35. Koechlin C, Maltais F, Saey D, Michaud A, LeBlanc P, Hayot M, Préfaut C. Hypoxia enhances muscle oxidative stress in chronic obstructive pulmonary disease. Thorax 2005;60(10):834-841.

36. Hayot M, Rodriguez J, Vernus B, Carnac G, Jean E, Allen D, et al. Myostatin up-regulation is associated with the skeletal muscle response to hypoxic stimuli. Mol Cell Endocrinol 2011;332(1-2):3847.
37. Hamnegard CH, Bake B, Moxham J, Polkey MI. Does undernutrition contribute to diaphragm weakness in patients with severe COPD? Clin Nutr 2002;21(3):239-243

38. Laghi F, Langbein WE, Antonescu-Turcu F, Jubran A, Bammert C, Tobin MJ. Respiratory and skeletal muscles in hypogonadal men with chronic obstructive pulmonary disease. Am J Respir Crit Care Med 2005;171(6):598-605

39. Ottenheijm CA, Heunks LM, Dekhuijzen PN. Diaphragm muscle fiber dysfunction in chronic obstructive pulmonary disease: toward a pathophysiological concept. Am J Respir Crit Care Med 2007; 175(12):1233-1240.

40. Serres I, Gautier V, Varray A, Préfaut C. Impaired skeletal muscle endurance related to physical inactivity and altered lung function in COPD patients. Chest 1998;113(4):900-905.

41. Garcia-Rio F, Lores V, Mediano O, Rojo B, Hernanz A, LópezCollazo E, Alvarez-Sala R. Daily physical activity in patients with chronic obstructive pulmonary disease is mainly associated with dynamic hyperinflation. Am J Respir Crit Care Med 2009;180(6):506512 .

42. Pitta F, Troosters T, Spruit MA, Probst VS, Decramer M, Gosselink R. Characteristics of physical activities in daily life in chronic obstructive pulmonary disease. Am J Respir Crit Care Med 2005;171(9): 972-977.

43. Pinto-Plata VM, Cote C, Cabral H, Taylor J, Celli BR. The 6-min walk distance: change over time and value as a predictor of survival in severe COPD. Eur Respir J 2004;23(1):28-33.

44. Solway S, Brooks D, Lacasse Y, Thomas S. A qualitative systematic overview of the measurement properties of functional walk tests used in the cardiorespiratory domain. Chest 2001;119(1):256-270.

45. Celli BR, Cote CG, Lareau SC, Meek PM. Predictors of survival in COPD: more than just the FEV1. Respir Med 2008;102(Suppl 1): 27-35.

46. Ong KC, Lu SJ, Soh CS. Does the multidimensional grading system (BODE) correspond to differences in health status of patients with COPD? Int J Chron Obstruct Pulmon Dis 2006;1(1):91-96.

47. Ong KH, Earnest A, Lu SJ. A multidimensional grading system (BODE index) as a predictor of hospitalization for COPD. Chest 2005;128(6):3810-3816. 